\title{
新疆水利水电工程混凝土施工管理技术与方法探究
}

\author{
木巴热克・阿不利孜 \\ 新疆博乐市水利管理站 \\ DOI:10.32629/hwr.v4i6.3039
}

[摘 要] 新疆地区基于地理环境因素的影响,导致水利水电工程建设期间面临着诸多困难,为确保工程项目投入后的安全应用,对于工程质量也 提出了较高的要求标准。混凝土作为水利水电工程中所应用的主要材料,其施工管理如何将会直接影响到整个工程的质量。混凝土配比对于其 施工质量至关重要,但在新疆地区某些水利水电项目建设期间,还存在着配比缺乏合理性的问题。为此,文章中以新疆独特的地理环境作为基础, 探究水利水电工程中混凝土施工管理的有效策略及相关技术。

[关键词] 新疆; 水利水电工程; 混凝土施工管理; 技术

水利水电工程属于社会基础建设重点项目, 施工质量如何会直接影响 到周围人民生命财产安全。新疆地区的地质条件并不利于水利水电项目的 施工, 为此, 在混凝土施工中需要加强关注。加强对混凝土施工技术的应用 及合理性控制, 能够在一定程度上延长项目使用寿命, 另外对于确保水利 水电工程的应用安全性也具有重要意义。

\section{1 水利水电工程混凝土施工简述及管理重要性}

1.1 水利水电工程混凝土施工简述

水利水电工程建设期间, 混凝土施工技术主要包括搅拌、运输、浇筑、 养护。以其中较为重要的浇筑而言, 需要应用专业化的混凝土振捣机完成 振实工作, 其目的在于控制空洞的出现。最后还应该对混凝土做有效养护, 借由此来提升混凝土质量及使用周期。在混凝土搅拌上, 具体为施工前操 作, 结合工程状况对混凝土混合料做充分搅拌, 从而达到保障混凝土质量 的效果。在混凝土的运输环节, 水利工程现场与摚拌现场的应用立足点不 同, 为此, 应该保障混凝土的运输安全。

1.2 水利水电工程混凝土施工管理重要性

第一, 计划编制可行性, 对于工程投资及进度等均具有影响作用。各项 计划均用指标的实现作为评估标准, 指标是预期目标与水平, 计划指标之 间也存在着密切关联, 构架起科学的指标体系是实现计划管理的关键。第 二, 针对如何控制计划缺乏合理性的问题, 需要具备一定计划意识, 所有工 作均需要结合目标的实现设计出具体措施, 积极创造条件促使其实现。计 划在设计后则必须要贯彻落实, 在执行期间掌握整体生产经营目标, 加强 控制, 确保其能够适应各种情况转变, 维持计划执行稳定性。

\section{2 新疆水利水电混凝土施工管理所在不足}

2.1混凝土配比可行性有待提升

混凝土配比对于其施工质量至关重要, 但在新疆地区某些水利水电项 目建设期间, 还存在着配比缺乏合理性的问题, 也是此项工程建设的关键
性问题 ${ }^{[1]}$ 。一般条件中, 若混凝土的配比缺乏合理性, 会在一定程度上弱化 混凝土施工整合质量。在此种状况中, 需要在施工管理期间提升对混凝土 配比加以控制。在当前水利水电工程混凝土施工管理状况来看, 混凝土配 比多存在失衡现象。分析其原因可概括为, 新疆地区参与施工的技术人员 并未严格的遵循施工标准实现混凝土配合, 对追中混凝土施工硬度与浇筑 程度造成负面影响。另外, 在施工期间, 若未进行原材料的全面篮选, 则可 能会导致原材料中混入其他物质, 增加混凝土配比失衡程度。针对出现了 配比失衡的问题, 常规需要依据工程实际状况重新完成交办, 此种操作形 成了极大的材料浪费, 也可增加人力资源成本上的投入。

2. 2 原材料管理措施有待改进

水利水电工程混凝土施工期间, 会涉及到众多原材料的应用, 为尽量 确保混凝土施工管理质量, 则需要严格依据混凝土施工要求, 明确具有可 行性的原材料配比方案 ${ }^{[2]}$ 。但在当前水利水电工程混凝土施工管理状况来 分析, 多存在着原料管理措施落实不到位的现象。多种类型原材料自身性 能与实际配比影响到工程混凝土施工质量。而其中主要应用到的原材料 是混凝土原料水泥与石头以及沙子等, 若实际情况需要则需要增加部分 化学用品, 例如早强剂与缓凝剂等。基于混凝土原材料种类具有多样性 特征的影响, 导致水利水电工程混凝土施工管理工作开展存在着较大的 难度 ${ }^{[3]}$ 。若不具备有效的施工原材料管理, 则会进一步增加材料都是或是 效能弱化的问题。

2. 3 混凝土强度设计水平有待提升

在一般条件下, 水利水电工程混凝土施工期间, 基于混凝土材料混合 环节比例不同因素的干扰, 可造成混凝土自身强度的差异 ${ }^{[4]}$ 。若混凝土自 身强度较大, 可增加混凝土浇筑工作实施难度。若混凝土自身强度较小, 则建筑物自身的质量也无法保障, 包括容易受到损坏或是减少使用时间 等。现阶段水利水电工程混凝土管理中, 混凝土的强度设计缺乏合理性问

影响轴瓦稳定性的因素很多, 它涉及轴瓦设计、制造、检修及运行等 多个方面。通过本次对 $\# 1$ 轴承排查治理, 解决了机组启动过程中\# 1 轴承振 动大问题。由于\# 1 轴承为可倾瓦轴承, 当机组运行工况发生变化时, 其瓦块 能随着转速、载荷及轴承温度的不同而自由摆动, 具有较高稳定性, 一般认 为在汽轮机冲转过程中不会发生轴承失稳情况。若是在机组启动升降速过 程中\#1轴承振动出现异常波动, 可以将可倾瓦失稳作为一个排查疑点。机 组检修期间应确保轴瓦安装数据合格, 并做好现场轴承箱洁净化管控。

[参考文献]

[1] 寇胜利. 汽轮发电机组的振动及现场平衡 [M]. 北京: 中国电力出版 社,2007:01.

[2]施维新. 汽轮发电机组振动及事故 [M]. 北京: 中国电力出版 社,1998:10.

[3]王云飞.660MW汽轮机中压主汽门卡澀原因分析与处理[J].机电信 息,2011,(09):73+76.

[4]任怀良, 陆斌杰.600MW汽轮机主汽门的优化设计 [ J ]. 热力透 平, $2008,(03): 162-165+178$.

[5]刘恒,王杨华,魏飞.65MW汽轮机组中压主汽门异常在线处理 [J].冶 金动力,2018,(03):42-44.

[6]崔志勇, 赵旭东, 卢祥远, 等.600MW汽轮机再热主汽门轴向密封改造 [J].机械,2017,44(07):32-36+50. 
题频繁出现, 与施工技术人员没有对混凝土强度进行有效设计或管理等存 在重要关联。若混凝土硬度未能够达到水利水电工程混凝土施工管理要求, 则会对工程施工质量造成不可估计的影响, 轻则会带来经济损失, 重则会 威胁到周边人民的生命安全。

\section{3 新疆水利水电混凝土施工管理有效技术及方法}

3.1 水闸地板施工期间混凝土应用

针对水闸地板的施工可总结为, 脚手架搭建、模型建立、钢筋扎捆 等 ${ }^{[5]}$ 。常规情况下, 在施工活动开展前, 需要做好找平工作, 以此来保障地 基的相对水平。做水闸地板建模可在水闸四方做侧模板构建, 经由支撑木 桩进行固定。为控制浇筑环节出现地板层面沉降情况, 多会应用麻面的方 式进行浇筑。经由预制的混凝土在死冷状态中做钢筋固定工作, 经由铅丝 帮吊做同地板舱面的脚手架做好防止钢筋变形工序。

3.2 混凝土大坝施工技术应用

第一, 大坝分缝分块技术。现阶段新疆地区水利水电工程建设期间, 多数大坝均在应用混凝土浇筑办法, 大坝无法一次性完成, 为此, 分块浇筑 的办法应用也较为频繁, 常见为错缝分块与通仓分块等 ${ }^{[6]}$ 。错缝分块浇筑 结合一定方向与高度将坚峰错开, 浇筑快常规较小, 对温度控制的要求不 高。通仓分块浇筑常规情况下不涉及到冷却水管埋设环节, 但要求对温度 做适当控制, 其原因在于, 通仓分块浇筑长度较大, 若操作不合理则会出现 温度裂缝。第二, 接缝灌浆管路系统布置。一般条件下, 混凝土大坝接缝灌 浆管理系统设计包括骑缝式灌浆、重复式灌浆、盒式灌浆等。盒式灌浆系 统多应用到纵缝灌浆中, 重复式灌浆多应用在不堵塞管道需要重复灌浆的 作业环境中。接缝灌浆的压力常规选择为 $0.2 \mathrm{MPa}$, 多不需要对浆口的灌浆 压力作出控制, 在接缝灌浆前需要核算代表性坝块的应用。在选择大坝接 缝灌浆顺序环节, 应该结合水泥结石的受力情况, 关注到坝块的实际状况, 坚持先横风后纵缝的基础原则 ${ }^{[7]}$ 。

3. 3 混凝土养护技术应用

混凝土浇筑工作开展后, 需要对混凝土作出适当的养护, 常见的养护 方式包括自然养护法、喷涂薄膜法、包裹塑膜法。以上三种办法可直接完 成混凝土养护, 可确保混凝土质量。常规条件下需要在浇筑工作完成后半 天后对混凝土实施必要的养护, 可确保建筑混凝土湿度。依据工程具体要 求, 对混凝土做养护, 所能够达到的养护效果也存在一定差异。但值得注意 的问题是, 养护工作开展期间, 需要考虑施工期间的气温与湿度等因素, 其 目的在于保障混凝土硬化条件符合工程标准。

3. 4 混凝土搅拌技术的合理应用

混凝土施工期间搅拌工作对其质量具有直接影响, 需要参与施工的技 术人员了解混凝土搅拌需求, 对混凝土材料自身性能作出可靠评估, 为混 凝土施工方案明确提供数据上的支持 ${ }^{[8]}$ 。综合混凝土材料性能分析结果, 选择适当的混凝土摚拌方式。在此项工作开展前需要寻找到符合标准的混
凝土摚拌设备, 在满足工程具体条件下, 需要将混凝土摚拌温度控制到 $15^{\circ} \mathrm{C}$ 之下, 其摚拌温度控制到 $80^{\circ} \mathrm{C}$ 左右。若实际条件允许则可应用饮用水, 在应用其他水源的条件下, 需要对水质作出检测, 保障混凝土质量能够符 合水利水电工程需求。另外, 在混凝土搅拌前, 应该对应用的材料性质进行 分析, 对各种材料的应用情况做好记录, 便于后期检查。

\section{4 结论}

在新疆地区水利水电工程建设期间, 会涉及到众多施工项目。以水利 水电工程建设期间的混凝土施工而言, 混凝土施工技术主要包括摚拌、运 输、浇筑、养护。在一般条件下, 水利水电工程混凝土施工期间, 基于混凝 土材料混合环节比例不同因素的干扰, 可造成混凝土自身强度的差异。若 混凝土自身强度较大, 可增加混凝土浇筑工作实施难度。文章有总结到, 基于种种因素的影响, 导致新疆地区水利水电中混凝土施工管理还存在着 一系列问题, 包括混凝土配比不合理、管理缺乏科学性等。此种情况的存 在会极大的影响到水利水电项目建设质量, 以及后期投入应用后的安全 性。为此, 建议新疆水利水电项目建设相关部门, 必须要加强对混凝土施工 技术以及管理工作的关注。借助于先进技术的引进以及合理的管控, 为水 利水电工程项目建设奠定良好的基础。

\section{[参考文献]}

[1]童新东.水利水电工程混凝土施工管理技术与方法探究 [J].低碳世 界,2019,09(07):136-137.

[2]余祖海.水利水电工程混凝土施工管理技术与方法探究 [J].城市周 刊,2019,05(14):85-85.

[3]Wang X . Study on the Late-stage Support Path of Migrants of Water Conservancy and Hydropower Engineering in Suining, Sichuan Province[C]// International Conference on Culture.2018.

[4]李岩波.浅析混凝土施工技术在水利水电施工中的应用 [J].建筑工 程技术与设计,2018,07(04):2529.

[5]洪亮.水利水电工程混凝土施工管理技术与方法探微 [J].城市建设 理论研究:电子版,2018,07(11):15-18.

[6]孙炎.混凝土施工技术在水利水电施工中的应用探讨 [ J ].山东工业 技术,2018,(014):142.

[7]黎青松.水利水电工程中混凝土防渗墙施工技术的运用[J].四川建 材,2018,05(01):151-152.

[8]Wen-Yuan W . Discussion on the Construction Technology of Roller Compacted Concrete Dam in Water Conservancy and Hydropower Project[J]. management \& technology of sme, 2018,07(09):14-15.

作者简介：

木巴热克・阿不利孜(1972--),女,新疆博乐市人,维吾尔族,本科, 中级工程师,研究方向：水利工程；从事工作：水利工程运行管理。 